\title{
PACIENTŲ SAUGOS KULTŪROS VEIKSNIŲ ANALIZE் ANESTEZIJOS IR INTENSYVIOSIOS TERAPIJOS SKYRIUOSE
}

\author{
Elena Petrauskaitė, Aldona Mikaliūkštienè \\ Vilniaus universiteto Medicinos fakulteto Sveikatos mokslu institutas
}

\begin{abstract}
Raktažodžiai: saugos kultūra, požiūris ị saugą, pacientų saugos kultūra, intensyvioji terapija.

Santrauka

Pacientų sauga yra vienas iš pagrindiniu kokybiškos priežiūros elementų. Medicininès klaidos dèl nesaugios praktikos yra viena iš dešimties pagrindinių negalią ir mirtį sukeliančių priežasčių pasaulyje, siejamos su didele finansine žala valstybei ir gydymo ịstaigoms. Sveikatos priežiūros specialistų vaidmuo užtikrinant pacientų saugą yra vienas svarbiausių, todèl svarbu išanalizuoti medicinos darbuotojų požiūrị ị saugos kultūrą. Dèl ịvairių ir sudètingų medicininių procedūrų gausos, intensyviosios terapijos skyriai (ITS) yra laikomi vieni jautriausių medicininèms klaidoms. Saugos kultūros gerinimas darosi vis svarbesnis ir aktualesnis uždavinys pasaulyje.

Darbo tikslas - apžvelgti ir pateikti naujausios literatūros duomenis apie pacientų saugos kultūrą anestezijos ir intensyviosios terapijos skyriuose.
\end{abstract}

\section{Ivadas}

Pasaulio sveikatos organizacijos (PSO) duomenimis, dèl nesaugios sveikatos priežiūros pasaulyje kiekvienais metais ịvyksta 134 milijonai nepageidaujamų ịvykių, iš kurių apie 2,6 milijonai baigiasi pacientų mirtimi [1]. Manoma, kad medicininès klaidos dèl nesaugios praktikos yra viena iš dešimties pagrindinių negalią ir mirtị sukeliančių priežasčių. Medicininès klaidos daro didelę finansinę žalą valstybei ir gydymo įstaigoms. Paskaičiuota, jog apie 15 proc. ligoninès biudžeto išlaidų susijusios su nepageidaujamais įvykiais [1]. Yra duomenų, kad beveik 50 proc. medicininių klaidų buvo galima išvengti. Prevencijos priemonių ir pasekmes mažinančių strategijų taikymas gali sumažinti žalos naštą iki 15 procentų [1] ir pagerinti paciento ligos baigti [2]. Dèl reanimacijos ir intensyviosios terapijos skyriu (RITS) veiklos kompleksiškumo ir sudètingumo manoma, kad tai skyriai, kuriuose nepageidaujami ịvykiai gali ịvykti dažniausiai [3]. 2019 metais Pasaulio sveikatos asamblèja nutarè, jog pacientų sauga yra vienas iš pagrindinių kokybiškos priežiūros elementų, todèl organizacijos narès skatinamos prioretizuoti pacientų saugą, kurti ir puoselèti saugos kultūrą sveikatos priežiūros sektoriuje [2]. 27 Europos Sajungos šalys, tarp jų ir Lietuva, siekdamos pagerinti pacientų saugą, susivienijo bendram projektui „Europos Sajungos pacientu saugos tinklas" (EUNetPaS) [4]. Projekto tikslas - skatinti ir plèsti bendradarbiavimą pacientų saugos srityje, puoselèti pacientų saugos kultūrą ir skatinti keitimąsi informacija bei švietimą, sustiprinti veiklos koordinavimą ir nuoseklumą ES lygmeniu [4].

Lietuvos Respublikos sveikatos apsaugos ministro ịsakymu 2004 m. buvo patvirtinta Sveikatos priežiūros kokybès užtikrinimo 2005-2010 m. programa, aprèpusi esmines problemines kokybès sritis, iš kurių viena svarbiausiuju - pacientų sauga [5]. 2007 m. sveikatos apsaugos ministro patvirtintos Sveikatos priežiūros kokybès užtikrinimo programos priemonès apima konkrečius uždavinius pacientų saugai gerinti [5].

Saugos kultūros gerinimas darosi vis svarbesnis ir aktualesnis uždavinys pasaulyje. Atlikti tyrimai keičią saugos kultūros suvokimą, atsiranda naujasis požiūris, kuriam būdinga skaidri klaidų pranešimo sistema, žalos atlyginimo be kaltès modelis ir įsitikinimas, kad klaidos darbe neišvengiamai nutinka [6]. Kreipiamas demesys i kitas saugos kultūros sudedamąsias dalis: komunikaciją, komandinį darbą, atsparumą stresui ir su tuo susijusias klaidas [7].

$2018 \mathrm{~m}$. Valstybinio audito ataskaitoje „Asmens sveikatos priežiūros paslaugų kokybė: saugumas ir veiksmingumas" konstatuojama, kad Lietuvoje, lyginant su kitomis šalimis (pvz., JAV), privalomų registruoti nepageidaujamų ịvykių sąrašas yra labai trumpas [8]. Nustatyta, jog didžioji dalis medicininių klaidų susijusios su darbuotojų informuotumu, žmogiškaisiais veiksniais vertinant paciento būklę, priimant klinikinius sprendimus ir darant klinikines išvadas [9]. Valstybinio audito duomenimis, apytiksliai 60 proc. potencialiu nepageidaujamų ìvykių grupių Lietuvoje nèra numatyta registruoti ir vertinti [8]. Priešingai negu Ispanijoje, Lietu- 
voje nefiksuojamos sveikatos priežiūros sistemos spragos ir neregistruojami ịvykiai, kurie galejo sukelti žalą, tačiau jų buvo išvengta [10]. JAV nepageidaujamų įvykių registras apima nepageidaujamus ịvykius, susijusius su išsilavinimu, komunikacija, organizacine kultūra ir kitomis saugos kultūros sritimis [8]. Lietuvos teisinėje bazejje vyrauja siauras požiūris ị pacientų saugą, kai saugos kultūra yra labai plati koncepcija, kurią sudaro net tik išoriniai (istatymai, fizine darbo aplinka, darbo priemonès), bet ir vidiniai veiksniai (darbuotojų vertybès, pasitenkinimas darbu, komandinis darbas) [6]. Norint pagerinti saugos kultūrą ir gydymo bei slaugos kokybę, svarbu pažinti ligoninėse vyraujančią saugos kultūrą, išsiaiškinti esamus sistemos trūkumus, silpnąsias vietas. Tikètina, kad atlikti tyrimai gali padèti rasti lengvus sprendimo būdus saugos kultūrai pagerinti.

Lietuvos mastu saugos kultūros tyrimų atlikta nedaug. Keliuose iš jų vertinama RITS saugos kultūra. Vieną tyrimą atliko Valstybinè akreditavimo sveikatos priežiūros tarnyba prie sveikatos apsaugos ministerijos, kuriame analizavo saugos kultūrą ịvairių Lietuvos ligoninių RITS ir kito profilio skyriuose, tačiau šio tyrimo duomenys nèra viešai skelbiami [11], todèl siekiama ịsigilinti ị šią tematiką.

Tyrimo tikslas - apžvelgti ir pateikti naujausios literatūros duomenis apie pacientų saugos kultūrą anestezijos ir intensyviosios terapijos skyriuose.

\section{Tyrimo medžiaga ir metodai}

Straipsnių paieška buvo atlikta PubMed (Medline), Google Scholar duomenų bazėse, ReasearchGate ir eLab duomenų paieškos sistemose. Naudoti raktiniai žodžiai patient safety, safety culture, safety attitudes, intensive care unit. PubMed duomenų bazejje pasinaudota MeSH terminais, o kitose duomenų bazèse paieškai atlikti naudoti jungtukai AND ir OR. Atlikta paieška, naudojant lietuviškus paieškos raktažodžių atitikmenis: saugos kultūra, požiūris ị saugą, reanimacijos - intensyviosios terapijos skyrius. Straipsniai buvo filtruojami pagal publikavimo datą: ieškota ne senesnių negu 10 metų straipsnių. Paieškos metu atrinkti 8 viso teksto straipsniai, tinkami ap̌̌valgai.

\section{Tyrimo rezultatai}

Streso ịtaka požiūriui ị pacientų saugą. ITS slaugytojos atpažįsta nuovargio neigiamus padarinius darbo rezultatams, tačiau neigia, jog pavargusios dirba mažiau efektyviai [12]. Vyresnis amžius ir didesnis darbo stažas siejamas su didesniais streso atpažinimo įverčiais [13]. Nustatyta, jog darbe patiriamas stresas daro ịtaką asmeninių santykių kokybei, o darbinis klimatas tiesiogiai susijęs su požiūriu ị saugumą ir i sveikatą [14]. Tyrimai rodo, kad pagrindiniai stresoriai skirtingose šalyse yra panašūs, o tarp svarbiausių yra darbo krūvis ir darbas su terminalinès būklès pacientais [14]. Ivardijamos ir kitos stresą keliančios priežastys: grasinimai, kad pablogès darbo sąlygos; netikèti, staigūs darbinių situacijų pokyčiai; bloga vadovavimo kokybé; netinkamas darbo organizavimas; atsakomybė už nevaldomas situacijas darbe; konfliktai su pacientais; informacijos stoka apie pacientų būklę [15]. Pasak tyrèjų, personalas geba ịvertinti patiriamo streso priežastis, tačiau ligoninès administracija neskiria didelio dèmesio darbuotojų būklès analizavimui ar darbo sąlygų gerinimui [14]. Galima teigti, kad darbuotojai nesijaučia saugiai darbe, todèl prastėja jų darbo kokybė.

Komandinio darbo ir požiūrio ị saugą sąsajos. Darbuotojų požiūris ị komandinị darbą yra teigiamai susijęs su darbuotojų požiūriu ị sveikatos priežiūros paslaugų kokybę ir pacientų saugą [5]. Ivairių šalių atlikti tyrimai rodo, kad komandinis darbas ir pacientų sauga yra du tarpusavyje susiję veiksniai, kurie turi įtakos sveikatos priežiūros personalo ir pacientų bendradarbiavimui. Užtikrinus šiuos du veiksnius, sumažėja nepageidaujamų ịvykių ir su jais susijusių išlaidų, padideja darbo našumas, pagerẻja sveikatos priežiūra [16]. Tyrimais nustatyta, kad esant profesionaliai, gerai susibendravusiai, gebančiai perprasti vieni kitu veiksmus komandai, gerèja pacientų sauga, darbo metu išvengiama klaidų [7]. Geras bendradarbiavimas tarp to paties skyriaus ir kitų skyrių darbuotojų taip pat teigiamai veikia pacientų saugos kultūrą. Tyrime nustatyta, kad ITS gerinant bendravimą pamainų perdavimo metu ir susisteminat perduodamą informaciją, pacientų perkèlimo ị kitą skyrių metu pagerèja pacientų saugos kultūros vertinimas ir priežiūros efektyvumas [17]. ITS slaugytojos bendradarbiavimą ir komunikaciją vertina labiau teigiamai su kitomis komandos slaugytojomis negu su komandos gydytojais ar kitais darbuotojai [18]. Gydytojai pozityviau vertina bendradarbiavimą su slaugytojomis negu slaugytojos su gydytojais [13]. Pastebima, kad silpniausios asmens sveikatos priežiūros ịstaigos pacientų saugos sritys neteisingas atsakas ị klaidą; komandinis darbas tarp skyrių; komunikacijos atvirumo trūkumas [19].

Vadovybės požiūris ị saugą. I. Brasaitès ir kt. atlikto tyrimo rezultatai parodè, kad slaugytojai aukščiausiais teigiamais balais vertina pasitenkinimą darbu, o žemiausiais - vadovybès požiūrị i saugą [20]. Kiti tyrimai patvirtina, kad Lietuvos sveikatos priežiūros specialistai yra patenkinti savo darbu, komandinio darbo aplinka, tačiau, darbuotojų požiūriu, vadovybès dèmesys pacientų saugai yra nepakankamas [21]. Lietuvos tyrejjų duomenimis, ITS gydytojai statistiškai reikšmingai aukštesniais balais vertino vadovų požiūrị i saugą, lyginant su slaugytojais [22]. Tyrimų duomenimis, ITS specialistai apie klaidas nepraneša dèl bausmių baimès. Baimę sustiprina nuomoné, jog vadovai ne su visais darbuotojais elgiasi vienodai [23]. JAV moksliniai tyrimai 
parode, jog pacientų saugos gerèjimas vyksta palengva, tačiau moksliškai pagrịsta, jog vadovų dedamos maksimalios pastangos gerinti pacientų saugą ši pokyti gali padidinti net 5 kartus [19]. Tyrimai rodo, kad asmens sveikatos priežiūros istaigose, kuriose vadybos ir medicininis personalas glaudžiai bendradarbiavo nustatydami kokybès strategiją, gavo geresnius klinikinius rezultatus [19]. Teigiama, kad vadovybės ir medicinos personalo bendradarbiavimo gerinimas turi teigimos itakos pacientų saugos kokybei. Manoma, kad vieni svarbiausių veiksnių, užtikrinačių pacientų saugą, yra specialistų komandinis darbas, atsiliepimai ir komunikacija apie NI, vadovo veiksmai, skatinant saugą.

Pasitenkinimas darbu. Užsienio autoriai nurodo, kad pozityvi saugos ir sveikatos kultūra siejama su pasitenkinimu darbu, sumažejusiu nedarbingumu dèl susižalojimų ir padidejusiu produktyvumu. Tyrimais nustatyta, kad saugos kultūrą, saugią praktiką ir pasitenkinimą darbu sieja statistiškai reikšmingas ryšys. Pastebèta, jog didesnę darbo patirtị turinčios ITS slaugytojos labiau teigiamai ịvertina pasitenkinimą darbu [12]. Teigiama, kad saugos kultūra, kartu su jaučiamu pasitenkinimu darbu, gali 44 proc. paskatinti saugios praktikos laikymąsi [5].

Darbo aplinkos ịtaka požiūriui ị saugą. Mokslininkų duomenimis, darbo aplinka daro didelę ịtaką pacientų priežiūros rezultatams. Palanki darbo aplinka siejama su mažesniu pacientų gaivinimo ir mirties dažniu, sumažejusiu pacientų šeimos narių skundų skaičiumi [24]. Studijų duomenimis, pozityvi darbo aplinka siejama su mažesniu profesinio perdegimo lygiu, didesniu pasitenkinimu darbu, sumažejusiu darbuotojų ketinimu išeiti iš darbo, geresniais pacientų priežiūros rezultatais bei geresne pacientų sauga [25]. Slaugytojos, dirbančios naktinėmis arba ịvairiomis paminomis, prasčiau vertina pacientų saugos kultūrą [26]. Nepalanki darbo aplinka (telefono skambučių trukdžiai) ir pamainų perdavimo sistemos nebuvimas sunkina pamainų perdavimą [23]. Tyrimais pastebima, jog jaunesni ITS darbuotojai, palyginti su vyresniais, statistiškai reikšmingai dažniau sutinka su teiginiu, jog pamainų keitimasis turi įtakos pacientų saugai [7].

Sveikatos priežiūros specialistų požiūris ị saugą. Atliktų tyrimų rezultatai rodo, kad visiems saugos kultūros vertinimo aspektams ịtakos turi socialiniai demografiniai rodikliai (išsilavinimas, profesija, darbo stažas ir kt.). Nustatyta, jog slaugytojai, turintys aukštajį neuniversitetinị išsilavinimą, geriau ịvertino pacientų saugos dimensijas, palyginti su turinčiais 11-20 metų darbo patirtị ir aukštesnijị išsilavinimą [21]. H. Abdou nustate, kad slaugytojai, turintys aukštajj išsilavinimą, labiau patenkinti darbu ir emociškai ịsipareigoję skyriui, kuriame dirba, nes jų darbas tiesiogiai veikia kitus žmones [27]. Pastebima, kad ilgiau skyriuje dirbantys ir vy- resni darbuotojai dažniau linkę kalbėti apie pacientų saugos problemas, darbe pasitaikančias klaidas ir nepageidaujamus įvykius [28]. Nustatyta, jog medikų, dirbančių daugiau nei 48 valandas per savaitę, dvigubai didesne širdies infarkto rizika, jie dažniau patiria nelaimingus atsitikimus darbe ir ne darbo vietoje, bei didesnị darbinį stresą. D. Krušinskaitès atlikto tyrimo duomenimis, darbe patiriamo streso dažnumas buvo reikšmingai susijęs su slaugytojų amžiumi ir darbo krūviu: stresinès situacijos dažnesnès jaunesnio amžiaus ir didesniu krūviu dirbantiems slaugytojams [29]. Galima daryti išvadą, kad ilgiau skyriuje dirbantys ir aukštesnị išsilavinimą turintys slaugytojai pacientų saugą vertina labiau teigiamai.

\section{Išvados}

1. Saugos kultūrą sveikatos priežiūros darbuotojai pripažįsta kaip svarbią saugios sveikatos priežiūros dalị.

2. Išanalizavus visas 6 pagrindines saugos kultūros dimensijų dalis pastebima, kad sveikatos priežiūros specialistai yra patenkinti savo darbu, teigiamai, ypač slaugytojai, vertina saugos kultūrą savo skyriuje, komandinị darbą ir darbo sąlygas. Saugą aukštesniais ịverčiais vertina didesnę darbo patirti ITS turintys darbuotojai ir tie, kurie nurodè turintys aukštesnị išsilavinimą, todèl atliekant tolesnius saugos kultūros tyrimus, būtų naudinga ištirti ir palyginti šių dviejų grupių specialistų nuomones ir išsiaiškinti, kas lemia šiuos skirtumus.

3. Vadovybès požiūris ị saugą ir darbuotojų atsparumas stresui vertinamas nenuosekliai. Teigiama, kad norint pagerinti saugos kultūrą, tyrẻjų dèmesys turètų būti labiausiai nukreiptas ị šias sritis.

\section{Literatūra}

1. WHO. Patient Safety. 2019. https://www.who.int/news-room/ fact-sheets/detail/patient-safety.

2. World Health Assembly. Global action on patient safety. SeventySecond World Heal Assem. 2019;22(10):809-15. https://dre.pt/ application/conteudo/115685379.

3. Muroi M, Shen JJ, Angosta A. Association of medication errors with drug classifications, clinical units, and consequence of errors: are they related? Appl Nurs Res 2017;33:180-185. https://doi.org/10.1016/j.apnr.2016.12.002

4. European Patients Forum. EUNetPas 2019. https://www.eupatient.eu/Projects/completed-projects/EUNetPaS/

5. Nepageidaujamų ivykių registravimo, stebėsenos ir prevencijos sistemos diegimas ir plètra Lietuvos asmens sveikatos priežiūros ịstaigose. Metodinis leidinys. Higienos institutas, 2015. ISBN 978-9986-457-43-5.

6. Hollnagel E, Nemeth CP, Dekker S. Remaining sensitive to the possibility of failuree. Resilience Engineering Perspectives. CRC Press 2008:352.

7. Piškinaitè G. Darbuotojų požiūrio ị komandinị darbą ir pacientų saugą vertinimas LSMUL Neonatologijos klinikoje. 
Kaunas: LSMU, 2019. https://www.lsmu.lt/cris/bitstream/20.500.12512/102963/1/Gintare Piškinaite.pdf

8. Asmens sveikatos priežiūros paslaugų kokybė: saugumas ir veiksmingumas. Valstybinio audito ataskaita Nr. VA2018-P-9-3-9. Lietuvos Respublikos valstybès kontrolè, 2018.

9. Clapper TC, Ching K. Debunking the myth that the majority of medical errors are attributed to communication. Med Educ 2020;54(1):74-81.

https://doi.org/10.1111/medu.13821

10. Brogienė D. Nepageidaujamų ịvykių sąrašas ir apibrezžimai. Higienos institutas: VP1-4.3-VRM-02-V-05-012, 2014.

11. Pilotinis pacientų saugos kultūros tyrimas. Valstybinè akreditavimo sveikatos priežiūros veiklai tarnyba prie Sveikatos apsaugos ministerijos, 2017. https://vaspvt.gov.lt/node/131.

12. Raftopoulos V, Pavlakis A. Safety climate in 5 intensive care units: a nationwide hospital survey using the Greek-Cypriot version of the safety attitudes questionnaire. J Crit Care 2013;28(1):51-61. https://doi.org/10.1016/j.jcrc.2012.04.013

13. Al Malki A, Endacott R, Innes K. Health professional perspectives of patient safety issues in intensive care units in Saudi Arabia. J Nurs Manag 2018;26(2):209-18. https://doi.org/10.1111/jonm.12536

14. Žaltauskienė G. Pacientų saugos kultūros vertinimo sąsajos su medicinos darbuotojų darbe patiriamo streso įveikos būdais $\mathrm{x}$ asmens sveikatos priežiūros paslaugas teikiančioje įstaigoje. Kaunas: LSMU, 2019

15. Lementauskaitė K. Medicinos personalo patiriamas profesinis stresas regioninejje ligoninèje. Kaunas: LSMU, 2015.

16. Singer S, Lin S, Falwell A, Gaba D, Baker L. Relationship of safety climate and safety performance in hospitals. Health Serv Res 2009;44(2P1):399-421. https://doi.org/10.1111/j.1475-6773.2008.00918.x

17. Sheth S, McCarthy E, Kipps AK, Wood M, Roth SJ, Sharek PJ, et al. Changes in efficiency and safety culture after integration of an I-PASS-supported handoff process. Pediatrics 2020;137(2).

https://doi.org/10.1542/peds.2015-0166

18. Alayed AS, Lööf H, Johansson UB. Saudi Arabian ICU safety culture and nurses' attitudes. Int J Health Care Qual Assur 2014;27(7):581-93.

https://doi.org/10.1108/IJHCQA-04-2013-0042

19. Budrikaitė R. Požiūrio ị pacientų saugą ir gero valdymo principų ígyvendinimo vertinimas $\mathrm{x}$ asmens sveikatos priežiūros istaigoje. Kaunas, 2019.

20. Brasaitė I, Kaunonen M, Martinkènas A, Suominen T. Health care professionals' attitudes regarding patient safety: crosssectional survey. BioMed Central Research Notes 2016; 9(177):1-7. https://doi.org/10.1186/s13104-016-1977-7 https://doi.org/10.1186/s13104-016-1977-7

21. Kulevičiūtè L, Vasyliūtė I, Brasaitè I. Slaugytojų požiūris ị pacientų saugą. Slauga, 2017; 27 (6):195-199.

https://doi.org/10.5200/sm-hs.2017.118

22. Asipauskienė V, Vaškelytė A. Vadovų požiūris ị saugą ir sau- gumo klimatą intensyviosios terapijos skyriuose: darbuotojų nuomone. Heal Sci 2020;30(6):152-8.

https://doi.org/10.35988/sm-hs.2020.157

23. Livorsi D, Knobloch M, Blue L, Swafford K, Maze L, Riggins $\mathrm{K}$, et al. A rapid assessment of barriers and facilitators to safety culture in an intensive care unit. 2016;63(3):372-6. https://doi.org/10.1111/inr.12254

24. Lee SE, Scott LD. Hospital nurses' work environment characteristics and patient safety outcomes: a literature review. Western Journal of Nursing Research 2018;40. https://doi.org/10.1177/0193945916666071

25. Guirardello E de B. Impact of critical care environment on burnout, perceived quality of care and safety attitude of the nursing team. Rev Lat Am Enfermagem 2017;25. https://doi.org/10.1590/1518-8345.1472.2884

26. Rizalar S, Topcu SY. The patient safety culture perception of Turkish nurses who work in operating room and intensive care unit. Pakistan J Med Sci 2017;33(2):374-9. https://doi.org/10.12669/pjms.332.11727

27. Abdou HA, Sabe KM. A baseline assessment of patient safety culture among nurses at student university hospital. World $\mathbf{J}$ Med Sci 2011;6(1):17-26.

28. Tomazoni A, Rocha PK, de Souza S, Anders JC, de Malfussi HFC. Patient safety culture at neonatal intensive care units: perspectives of the nursing and medical team. Rev Lat Am Enfermagem 2014;22(5):755-63.

https://doi.org/10.1590/0104-1169.3624.2477

29. Krušinskaitė D. Slaugytojų su darbu susijusio streso, pasitenkinimo darbu ir ketinimų keisti darbą vertinimas. Kaunas:LSMU, 2013.

\section{ANALYSIS OF PATIENTS SAFETY CULTURAL FACTORS IN THE DEPARTMENTS OF ANESTHESIA AND INTENSIVE CARE}

E. Petrauskaitè, A. Mikaliūkštienė

Key words: safety culture, safety attitude, patient safety culture, intensive care.

Summary

Patient safety is one of the fundamental elements of high-quality health care. It is evaluated that medical errors which occur due to unsafe medical practice are one of the 10 leading causes of death and disability worldwide, also such errors are linked with immense financial harm for a country and healthcare facilities. Healthcare specialists play an essential role when ensuring the safety of patients, therefore it is critical to assess healthcare specialists ${ }^{6}$ attitudes towards patient safety culture. Because of the extensive number of complex medical procedures, intensive care units are thought to be the most vulnerable to medical errors. The improvement of patient safety culture is currently becoming a more important and relevant task globally.

Correspondence to: aldona.mikaliukstiene@mf.vu.lt

Gauta 2021-03-09 